\title{
Cross-infection and infection control in dental clinics in Nablus and Tulkarm districts
}

\author{
Wafaa Menawi ${ }^{1,2,3^{*}}$, Areej Sabbah $^{4}$ and Lubna Kharraz ${ }^{5}$
}

\begin{abstract}
Background: Infection control had many developments in the COVID 19 (Coronavirus Disease 2019) pandemic, despite this, there were many complications in different health care facilities as well as dentists' clinics due to the lack of infection control knowledge and compliance failure. This study aimed to assess the level of knowledge and compliance with the infection control measures in the dental clinics in the Nablus and Tulkarm districts.

Results: The results showed that the total positive response regard all infection control domains were (70.0\%). Whereas the participants gave the highest positive response for personnel protective equipment i.e. gloving was (96.10\%). They gave the instruments related to controls the lowest responses, i.e. instruments sterilization was $(59.40 \%)$. The analyzed data showed significant statistical differences in the compliance with infection control measures between Nablus and Tulkarm districts " $\mathrm{p}<0.05$ " in the interest of dentists from Tulkarm.

Conclusions: In conclusion, the findings of this study showed that there is moderate compliance to infection control protocol in Nablus and Tulkarm dental clinics. Thus, there is a need to strengthen adherence to infection control measures.

Method: A universal sampling was used to assess the infection control program at the dental clinics in Nablus and Tulkarm Districts. The study sample involved 265 dentists. Data was collected using a questionnaire which has been sent via email between July and August 2020. Descriptive statistics, Chi-square test, One-way ANOVA and Post-Hock tests have been used. Statistical significance was set at " $\mathrm{P}<0.05$ ". Cronbach's alpha has been conducted to ensure the reliability and validity of the questionnaire.
\end{abstract}

Keywords: Infection control, COVID 19, PPE, Compliance, Knowledge, Palestine, Dentists

\section{Background}

Dental care practices are not risk-free [1]. A white-coat, a dental instrument, and a dental unit are susceptible to the splatter of blood, aerosol and saliva, trauma, or inoculation by contaminated instruments [2]. Thus, crossinfection and infection in dental clinics have become a major public concern [3]. As an action, health care practitioner needs to understand how are infectious diseases transmitted to minimize the risk [4]. Subsequently,

\footnotetext{
*Correspondence: w.menawi@najah.edu

1 Public Health Management Program, Faculty of Graduate Studies, AnNajah University, Nablus, Palestine

Full list of author information is available at the end of the article
}

appropriate safety precautions should be taken within the dental environment to prevent cross-infection transmission among patient-patient or patient-dental staff [5]. Today, the globe lives the ghost of Corona Virus disease, and it is the most appropriate time to emphasize the importance of cross-infectious disease and infection control measures [6]. In developing countries, infection control measures are either not documented, not followed, not funded by the government, or not existed, which makes the challenge of acquiring an infection during health care delivery increase in those countries [7]. Many studies have revealed that the neglecting of safety measures can cause adverse events and lead to hospital admission [8], increase in medical expenditure, permanent 
injuries, or even death [9]. These adverse events also can expose the dentist to a legal accountability allegation in courts, scandals of the press, and loss of money to compensate the affected patient if malpractice and substandard health care are applied in addition to the loss of license of the dental practice, while these adverse events could be manageable and avoidable [9]. Several factors may affect the compliance of dental practitioners to infection control measures. It could be the degree of education or knowledge [10], lack of incentives and costs [11], professional variables, socio-demographic, availability of infection control equipment, or access to this equipment [12].

The first manifestation of some infectious diseases appears as lesions in the oral cavity as TB (Tuberculosis), HIV (Human Immunodeficiency Virus), Syphilis, and Hepatitis [13] and COVID 19 [6]. The dental practitioner should have enough knowledge about these diseases to take precautions during dental care procedures [14]. The dental staff should implement Source Control Measures (SCM). Those measures, include hand hygiene, respiratory hygiene, cough etiquette, safe injection practices, safe handling of potentially contaminated equipment, and personnel protective equipment [15], in addition to maintaining a six-foot distance between patients in the waiting room to prevent the spread of the SARS-CoV-2 virus (Severe Acute Respiratory Syndrome Coronavirus) [16]. In Palestine, the obstacles impede the enjoyment of the highest attainable standards of health for Palestinians living under occupation, including barriers and lack of access to adequate health care [17]. A study conducted in the north of Palestine showed that visiting dental clinics and doing dental procedures are considered as the most significant risk factors for the acquisition of HBV (Hepatitis B Virus) infection [18]. But actually, the real estimation of cross-infection and infection control measures in these clinics is not clear as well as these measures are not controlled by the Palestinian Ministry of Health (PMH).

In this study, the authors evaluated the level of knowledge and compliance with standard precautions of infection control in dental clinics related to Nablus and Tulkarm districts, Palestine.

\section{Results}

\section{Participants characteristics}

As shown in Table 1, nearly two-thirds (58.9\%) of participants were males. The majority were non-specialists (75.1\%), and (56.2\%) were from Nablus district. A fifth of the participants (21.5\%) have been in dental practice for less than 5 years as well as being those practicing between 11 and 15 years and (14.3\%) of total participants
Table 1 Participants Characteristics

\begin{tabular}{lll}
\hline Gender & No. & $\%$ \\
\hline M & 156 & 58.9 \\
F & 109 & 41.1 \\
Total & 265 & 100.0 \\
Educational level & No. & $\%$ \\
Specialist & 66 & 24.9 \\
General & 199 & 75.1 \\
Total & 265 & 100.0 \\
Governorate & No. & $\%$ \\
Nablus & 149 & 56.2 \\
Tulkarm & 166 & 43.8 \\
Total & 265 & 100.0 \\
Years of experience & No. & $\%$ \\
$\leq 5$ & 57 & 21.5 \\
6-10 & 64 & 24.2 \\
11-15 & 60 & 22.6 \\
16-20 & 46 & 17.4 \\
>20 & 38 & 14.3 \\
Total & 265 & 100.0 \\
Ownership & No. & $\%$ \\
Private & 236 & 89.1 \\
Public & 24 & 9.1 \\
UNORWA & 5 & 1.8 \\
Total & $\mathbf{2 6 5}$ & \\
\hline & & 100.0 \\
\hline
\end{tabular}

have been practicing for more than 20 years. Finally, eighty-nine $(89.1 \%)$ of the total respondents were working in private clinics, $(9.1 \%)$ in governmental clinics and the least $(1.8 \%)$ were working in the united nations relief and works agency (UNRWA).

\section{Infection control protocol assessment domains}

Table 2 showed that the total compliances' regard all infection control domains mentioned in the study were (70.0\%). Whereas the participants gave the highest positive response for personnel protective equipment, gloving $(96.10 \%)$, face masking $(77.70 \%)$, protective clothing $(76.30 \%)$, hand washing $(76.10 \%)$, vaccination against HBV $(74.50 \%)$ and eye protection $(74.30 \%)$. They gave the instruments related to controls the lowest responses; instruments sterilization were (59.40\%), and aerosol control, accident management, and monitoring autoclave were $(55.1 \%, 55.30 \%$, and $47.20 \%)$ respectively except the surface decontamination with the responses of $(78.00 \%)$.

\section{Compliance of participants with infection control protocol according to governorates}

Data analysis by $\mathrm{T}$-test clarified that there were significant differences between the two Governorates (Nablus 
Table 2 Positive Response Percentage for Intended Domains

\begin{tabular}{llc}
\hline NO. & Intended Domain & $\begin{array}{c}\text { Positive } \\
\text { Response } \\
\%\end{array}$ \\
\hline 1. & & $74.50 \%$ \\
2. & Hepatitis vaccination & $96.10 \%$ \\
3. & Wearing Gloves & $77.70 \%$ \\
4. & Wearing a face mask during dental procedures & $74.30 \%$ \\
5. & Wearing eye protection & $76.30 \%$ \\
6. & Wearing Protective Clothing, head cap, and white coat & $76.10 \%$ \\
7. & Hand washing & $59.40 \%$ \\
8. & Instruments Sterilization & $47.20 \%$ \\
9. & Monitoring Autoclave & $78.00 \%$ \\
10. & Decontamination and Cleaning surfaces, using disposable protection parries & \\
11. & to cover some surfaces & $55.1 \%$ \\
Average of Positive Response Percentage for Intended & Domains. & $55.30 \%$ \\
\hline
\end{tabular}

and Tulkarm) " $\mathrm{p}<0.05$ " in seven domains; wearing gloves, wearing protective clothing, a head cap, and a white coat, hand washing, instruments sterilization, decontamination, and cleaning surfaces, using disposable protective barriers to cover some surfaces, aerosol control, and accident management. All these significant differences were in favor of Tulkarm versus Nablus governorate by referring to the means for the seven domains mentioned in Table 3 below.

\section{Compliance of participants with infection control protocol according to ownership}

The ANOVA F test (Table 4) showed that there were significant differences in wearing a face mask during a

Table 3 Compliance of Participants with Infection Control Protocol According to Governorate

\begin{tabular}{|c|c|c|c|c|c|c|}
\hline Domain & Governorate & $\mathbf{N}$ & Mean & S.D & $\mathrm{T}$ & P-value \\
\hline \multirow[t]{2}{*}{ Hepatitis vaccination } & Nablus & 149 & 0.72 & 0.304 & 1.381 & 0.168 \\
\hline & Tulkarm & 116 & 0.77 & 0.190 & & \\
\hline \multirow[t]{2}{*}{ Wearing gloves } & Nablus & 149 & 2.74 & 0.437 & 3.282 & ${ }^{*} 0.001$ \\
\hline & Tulkarm & 116 & 2.89 & 0.204 & & \\
\hline \multirow[t]{2}{*}{ Wearing a face mask during dental procedures } & Nablus & 149 & 2.12 & 0.805 & 1.179 & 0.239 \\
\hline & Tulkarm & 116 & 2.23 & 0.715 & & \\
\hline \multirow[t]{2}{*}{ Wearing eye protection } & Nablus & 149 & 1.99 & 0.771 & 1.272 & 0.204 \\
\hline & Tulkarm & 116 & 2.10 & 0.703 & & \\
\hline \multirow[t]{2}{*}{ Wearing Protective Clothing, head cap, and white coat } & Nablus & 149 & 2.11 & 0.635 & 2.121 & ${ }^{*} 0.035$ \\
\hline & Tulkarm & 116 & 2.26 & 0.525 & & \\
\hline \multirow[t]{2}{*}{ Hand washing } & Nablus & 149 & 2.19 & 0.575 & 3.851 & ${ }^{*} 0.000$ \\
\hline & Tulkarm & 116 & 2.44 & 0.422 & & \\
\hline \multirow[t]{2}{*}{ Instrument sterilization } & Nablus & 149 & 0.57 & 0.203 & 3.293 & ${ }^{*} 0.001$ \\
\hline & Tulkarm & 116 & 0.65 & 0.169 & & \\
\hline \multirow[t]{2}{*}{ Monitoring autoclave } & Nablus & 149 & 0.45 & 0.348 & 1.278 & 0.202 \\
\hline & Tulkarm & 116 & 0.50 & 0.353 & & \\
\hline \multirow{2}{*}{$\begin{array}{l}\text { Decontamination and cleaning surfaces, using disposable } \\
\text { protection barriers to cover some surfaces }\end{array}$} & Nablus & 149 & 2.15 & 0.647 & 3.269 & ${ }^{*} 0.001$ \\
\hline & Tulkarm & 116 & 2.39 & 0.552 & & \\
\hline \multirow[t]{2}{*}{ Aerosol control } & Nablus & 149 & 0.51 & 0.302 & 2.694 & ${ }^{*} 0.008$ \\
\hline & Tulkarm & 116 & 0.61 & 0.287 & & \\
\hline \multirow[t]{2}{*}{ Accident management } & Nablus & 149 & 0.65 & 0.336 & 2.967 & ${ }^{*} 0.003$ \\
\hline & Tulkarm & 116 & 0.76 & 0.251 & & \\
\hline
\end{tabular}

T-Test,${ }^{*} \mathrm{p}$-value $<0.05$ 
Table 4 Compliance of Participants with Infection Control Protocol According to Ownership

\begin{tabular}{|c|c|c|c|c|c|c|}
\hline Domain & Ownership & $\mathbf{N}$ & Mean & S.D & $\mathbf{F}$ & p-value \\
\hline \multirow[t]{3}{*}{ Hepatitis vaccination } & Private & 236 & 0.74 & 0.265 & 0.394 & 0.675 \\
\hline & Public & 24 & 0.78 & 0.248 & & \\
\hline & UNRWA & 5 & 0.80 & 0.112 & & \\
\hline \multirow[t]{3}{*}{ Wearing Gloves } & Private & 236 & 2.81 & 0.365 & 0.692 & 0.501 \\
\hline & Public & 24 & 2.76 & 0.350 & & \\
\hline & UNRWA & 5 & 2.65 & 0.224 & & \\
\hline \multirow[t]{3}{*}{ Wearing a face mask during dental procedures } & Private & 236 & 2.17 & 0.757 & 0.3443 & *0.033 \\
\hline & Public & 24 & 2.38 & 0.770 & & \\
\hline & UNRWA & 5 & 1.40 & 0.894 & & \\
\hline \multirow[t]{3}{*}{ Wearing eye protection } & Private & 236 & 2.08 & 0.722 & 5.993 & $* 0.003$ \\
\hline & Public & 24 & 1.88 & 0.850 & & \\
\hline & UNRWA & 5 & 1.00 & 0.000 & & \\
\hline \multirow[t]{3}{*}{ Wearing Protective Clothing, head cap, and white coat } & Private & 236 & 2.21 & 0.584 & 7.599 & $*^{*} 0.001$ \\
\hline & Public & 24 & 2.01 & 0.577 & & \\
\hline & UNRWA & 5 & 1.27 & 0.149 & & \\
\hline \multirow[t]{3}{*}{ Hand washing } & Private & 236 & 2.36 & 0.502 & 15.046 & $* 0.000$ \\
\hline & Public & 24 & 1.90 & 0.500 & & \\
\hline & UNRWA & 5 & 1.55 & 0.447 & & \\
\hline \multirow[t]{3}{*}{ Instruments Sterilization } & Private & 236 & 0.61 & 0.194 & 1.606 & 0.203 \\
\hline & Public & 24 & 0.59 & 0.183 & & \\
\hline & UNRWA & 5 & 0.46 & 0.039 & & \\
\hline \multirow[t]{3}{*}{ Monitoring Autoclave } & Private & 236 & 0.49 & 0.350 & 4.758 & $* 0.009$ \\
\hline & Public & 24 & 0.33 & 0.326 & & \\
\hline & UNRWA & 5 & 0.13 & 0.183 & & \\
\hline \multirow{3}{*}{$\begin{array}{l}\text { Decontamination and cleaning surfaces, using disposable } \\
\text { protection barriers to cover some surfaces }\end{array}$} & Private & 236 & 2.32 & 0.573 & 16.928 & $* 0.000$ \\
\hline & Public & 24 & 1.92 & 0.729 & & \\
\hline & UNRWA & 5 & 1.00 & 0.000 & & \\
\hline \multirow[t]{3}{*}{ Aerosol Control } & Private & 236 & 0.56 & 0.300 & 3.087 & $*^{*} 0.047$ \\
\hline & Public & 24 & 0.49 & 0.278 & & \\
\hline & UNRWA & 5 & 0.27 & 0.149 & & \\
\hline \multirow[t]{3}{*}{ Accident Management } & Private & 236 & 0.70 & 0.311 & 1.203 & 0.302 \\
\hline & Public & 24 & 0.67 & 0.282 & & \\
\hline & UNRWA & 5 & 0.50 & 0.000 & & \\
\hline
\end{tabular}

(ANOVA) F test, ${ }^{*}$ p-value $<0.05$

dental procedure, eye protection, monitoring autoclave and aerosol control domains attributed to the ownership variable " $\mathrm{P}<0.05$ ", the Post-Hoc test showed that the UNRWA group with means of 1.40,1.00, 0.13, 0.27 respectively were lower than all other groups

The same table presented that there were significant differences in wearing protective clothing, hand washing and decontamination and cleaning surfaces, using disposable protection barriers to cover some surfaces domain attributed to the ownership variable " $\mathrm{P}<0.05$ " and the Post-Hoc test showed that the private group with means of $2.21,2.36$ and 2.32 orderly were higher than all other groups

\section{Discussion}

\section{HBV vaccination}

Moderate compliance (74.50\%) was recorded toward HBV vaccination between participants in both districts. A similar study was conducted in Jordan (2020) and found that $(82.1 \%)$ of dental health care providers were compliant with vaccination against hepatitis B [19]. The current study revealed that there were no significant differences based on socioeconomic characteristics regarding HBV vaccination. Particularly, we are living under the greatness of the COVID 19 outbreak, so the medical teams wherever need to be armed with strong immunity as well as possible. 


\section{PPE (Personal Protective Equipment)}

In our study, the compliance with personal protective equipment was between high and moderate i.e. gloving was $(96.10 \%)$. In the same field, compliance with gloving among dentists was lower in Hebron (2017) (69.95\%) [20] and here we can say that knowledge and compliance are better among dental practitioners in Nablus and Tulkarm than those in Hebron or may be interpreted by COVID 19 epidemic as dentists in GAZA recorded high gloving compliance (98\%) [21] like Nablus and Tulkarm. The study also revealed that there were significant differences in wearing gloves attributed to the governorate variable (P-value $<0.05)$. The T-test showed that the Nablus district has a mean of (2.74) which is lower than the Tulkarm district (2.89). This means high knowledge about the importance of gloving among Tulkarm dentists maybe because of the awareness activities which were done by the dental association- Tulkarm branch to enhance the educational situation among its dentists. Also, results exhibited less adherence to mask -like in Gaza (70\%) [21] than Lebanese dentists which was recorded (89.1\%) in 2017 [12]. Also, the current study indicated significant differences in wearing a face mask during dental procedures attributed to the ownership variable (P-value $<0.05$ ). The Post-Hoc test showed that the UNRWA group, including the mean of (1.40) was the lowest of all other groups. This result means that there is a problem in dental care provided by UNRWA dental clinics, as these clinics provide dental services for a large number of refugees in more than five camps in two governates. Here, competent committees from $(\mathrm{PMH})$ or from UNRWA camps need to enforce the infection control system. We are still focusing on PPE, the compliance with eye protection is moderate among participants in the current study (74.30\%). This means fair knowledge about the importance and indicators for eye protection, compared with participants in a study that had been done among a group of military dentists in April 2009. As (50.57\%) never used eyeglasses or protective face shields [22]. A study in Hebron in 2017 revealed that only $(12.8 \%)$ of dental practitioners were compliant with eye protection [20], and (32\%) in Gaza [21].

The use of protective clothing, a head cap and a white coat is very important during dental care procedures. The study of Nablus and Tulkarm showed that (76.30\%) of the participants comply with Wearing Protective Clothing, head cap, and white coat.

Generally, the compliance with all (PPE) measures among the participants was $(81.1 \%)$ which means that there is a serious awareness of the global COVID 19 pandemic that we are all living till now. Khan and Chughtai (2020) come out that (HCWs) uses gloves and face masks more than any other (PPE) to protect them from infections and respiratory diseases. Thus, overall compliance and attitudes to the use of PPE were low [23]. The Nablus - Tulkarm study indicated significant differences in wearing eye protection that attributed to the governorate variable " $\mathrm{P}<0.05$ ". Where T-test showed the that Nablus group with a mean of (2.11) lower than the Tulkarm group with a mean of (2.26). These readings illustrate the need to encourage the competent committee in the Nablus district to provide more knowledge to dental practitioners about infection control measures. The study also revealed that there were significant differences in wearing protective clothing, a head cap, and a white coat attributed to the ownership variable $" \mathrm{P}<0.05^{\prime \prime}$. The Post-Hoc test showed that the mean of private clinics is higher than other groups. This may underline that the dentist in the private clinic is assiduous to appear in a good appearance in front of clients.

\section{Hand washing}

In the Nablus-Tulkarm study, the overall attended hand washing is moderate among participants (76.10\%). This is a low result compared with a study had been done in Jordan which revealed that hand washing after treatment was $(83.2 \%)$ and prior to starting treatment was $(66.3 \%)$ and about one-half (45.8\%) usually reported washing hands before wearing gloves [19]. The current study reported significant differences in handwashing attributed to the governorate variable $(\mathrm{P}$-value $<0.05)$. The $\mathrm{T}$-test showed that the Nablus district has a lower meaner (2.19) than Tulkam with a mean of (2.44). Again, significant differences in handwashing attributed to the ownership variable " $\mathrm{P}<0.05^{\prime \prime}$ were seen. The Post-Hoc test showed that UNRWA with a mean of (1.55) lower than other groups. This could be because of the high work pressure on UNRWA dental clinics and the huge numbers of patients visiting these dental clinics, causing a shortage of time to apply hand washing carefully after each dental task.

\section{Instrument sterilization}

Autoclaving is the most effective one of instrument sterilization in the dental field [24]. This way of sterilization received a high degree of compliance (94\%) among participants in Nablus and Tulkarm districts while the total instrument sterilization (decontaminant solution, washer disinfector, antiseptic and wrapping bags) was (59.4\%). This result is high compared with another one in a study among Lebanese dentists in 2017 which showed that steam autoclaving is the preferred means of sterilization (65\%) [12]. Another study was conducted in HebronPalestine in 2017 highlighted that the response regarding instrument sterilization was relatively low $(42.8 \%)$ where the level of compliance according to Sterilization and Disinfection of Patient Care Tools (SDT) was very high $88 \% 20$. 
The Nablus- Tulkarm study also revealed that there were significant differences in instrument sterilization attributed to the governorate level variable " $\mathrm{P}<0.05$ ". The T-test showed that the Tulkarm group with a mean $=0.65$ is higher than the Nablus group with a mean of (0.57). These results support what has been said previously that Tulkarm dentists have good knowledge about the means of infection control measures and they are keen to apply these measures more than Nablus dentists. This may be due to better awareness activities were done by the competent committees in Tulkarm district. These activities included medical conferences, regular and periodic inspections on dental clinics as Tulkarm district, or medical meetings, including lectures to raise the awareness of applying (ICM).

Significant differences in instrument sterilization attributed to the educational level variable $" \mathrm{P}<0.05^{\prime \prime}$ have been documented. The T- test showed that the specialist group with a mean $=0.55$ was lower than (GP) group with a mean $=0.62$. This means good knowledge among (General Practitioner) group about the importance of sterilization and at the same time seriousity in the application of this method is more than in the specialist group. It also revealed that there were significant differences in instrument sterilization attributed to the governorate level variable " $\mathrm{P}<0.05$ ".

\section{Autoclave monitoring}

In general, autoclave monitoring means that dentists should stop work completely in case of malfunction.

The result of the current study reflected fair knowledge about the ways of sterilization as they recorded (70.9\%) for the familiarity of autoclave monitoring methods, while they recorded a low positive response regarding the evaluation of the autoclave using chemical and biological as a whole (47.20\%). A significant difference in monitoring autoclave attributed to the ownership variable "P $<0.05$ ". The Post-Hoc test of the private group with a mean (0.49) was higher than other groups. This result may emphasize that they are assiduous to appear in a good appearance in front of their patients besides the practitioner.

\section{Decontamination and cleaning surfaces, using disposable protection barriers}

Environmental surfaces are those that do not come in contact directly with patients, but they can play a major role in transmitting the pathogens [25]. This study showed that a moderate percentage $(78.0 \%)$ of participants do decontamination and clean surfaces and use disposable protection barriers to cover some surfaces, a high percentage $(91.7 \%)$ of them used disinfectant to clean surfaces away from patient contact between patients, comparing that with other dentists in which they used disinfectant agents by (28.9\%) [26]. Our study has a high positive result in this field that mirrored a high awareness and knowledge about the importance of disinfection in the dental environment. Also, (80.0\%) of all participants regard covering surfaces that can't be decontaminated which in another study were used by (70.2\%) of private dental clinics [19]. The result of this study also reflected good compliance to cleaning and disinfection. As $(68.00 \%)$ of all participants cover light cure with special bags and (73.30\%) of them use disposable protection barriers to cover the dental unit chair. These two environmental surfaces are highly touched by dentists and staff hands. So it can be the main source of bacterial transmission. This study showed that (77.0\%) of all participants discard the disposable protection barriers after finishing the procedure. This moderate result is better than the result documented by Idris (2012) in which none of the study dentists used plastic barriers to cover the clinical contact surfaces [27]. These moderate responses have to be increased by enhancing knowledge among dentists and their staff and by informing patients about the curiosity of seeing the dentist or the assistant changes these disposal barriers. The study analysis exhibited that there were significant differences between Nablus and Tulkarm dental clinics in favor of Tulkarm clinics in decontamination and cleaning surfaces and using disposable protection " $\mathrm{P}<0.05$ ". Tulkarm clinics $($ Mean $=2.39)$ have decontamination and cleaning and using disposable protection more than Nablus clinics $($ Mean=2.15). These repeated results among all infection control domains confirm that Tulkarm's dental clinics are superior over those of Nablus's in terms of commitment to applying infection control measures, this commitment may come from high knowledge among Tulkarm dentists or continuous and frequent inspection of these dental clinics by stakeholders (dental association- Tulkarm branch or (PMH). There were also significant differences in decontamination and cleaning surfaces and using disposable protection barriers to cover some surfaces among participants attributed to the ownership variable "P $<0.05$ ". The Post-Hoc test showed that UNRWA dental clinics with a mean (1.00) were the lowest group in applying decontamination compared with other dental clinics. This result enforces what we noticed in the handwashing domain that when there is a large number of clients and patients visiting clinic per day (5 working hours). This will lead to drowse in order to disinfect and clean between patients. 


\section{Aerosol control}

All dental care using dental handpieces can form aerosol and splatter which are commonly impured with bacteria, fungi, viruses or blood [28]. A rubber dam is one of the many ways that can prevent the spreading of contaminated aerosol during dental procedures [29]. The participants of this study showed low compliance regard using rubber dams $(31.30 \%)$, but they were better than dentists in other studies which indicated (23.8\%) [30] and (2.4\%) [27] usage of rubber dams. The low percentage in the current study can be because of low knowledge about the importance of such a device. So, a highly concentrated effort should be made by competent committees' regard to using a rubber dam. The High-Volume Evacuator is another method was used during dental care procedures to prevent aerosol contamination by suctioning a large amount of blood and saliva that is secreted during headpiece working [28]. The participants of the current study showed a high degree of compliance with (HVE) $(86.80 \%)$, this is a good result compared with another one in which (28.6\%) of public hospitals use high volume evacuation hospitals compared to (19.4\%) in academic institutions [19]. Another study revealed that (61.6\%) did not use high vacuum suction [27]. The good result may come from the point that (HVE) is connected with a dental chair so the dentist doesn't need to buy such a device separately, but there is a need for reinforcing using (HVE) by increasing knowledge. Protective Mouth Rinse (PMR) with $(0.2 \%)$ chlorhexidine is also another method to prevent the spreading of splatter during dental care procedures. A study revealed that (PMR) can reduce the number of pathogens in the dental patient's mouth if they used gargling agents [31]. (47.20\%) of participants in the current study were using this method (PMR) which was a low percentage. In another study, two-thirds of dental practitioners would ask their dental patients to use a (PMR) before starting the treatment [32]. This low percentage in the current study may be attributed to the expensive price of such rinse, low knowledge about the use, and the importance of this method. Aerosol control in general between participants was (55.1\%), this result is very important to be taken into consideration by the competent committees, because, most infectious diseases are transmitted by contaminated air inhalation especially nowadays while we are living the ghost of COVID-19. Significant differences in aerosol control among participants were attributed to the governorate variable (P-value $<0.05)$. The $\mathrm{T}$-test showed that dental clinics in Nablus district with means $=0.51$ are lower in applying aerosol control than those of Tulkam with a mean $=0.61$. On the other hand, there were significant differences in aerosol control among participants attributed to the years of experience variable $" \mathrm{P}<0.05^{\prime \prime}$. The Post-Hoc test showed that the group of ( $\leq 5$ years) with a mean $=0.61$ were the higher in applying aerosol control among others. Finally, in terms of this domain, there were significant differences in aerosol control among participants attributed to the ownership variable " $\mathrm{P}<0.05^{\prime \prime}$. The PostHoc test showed that private clinics with mean $=0.56$ were the highest to apply aerosol control. This may indicate the desire of dental customers to receive their treatment in private clinics, which sometimes contributes to their income. But in the public and UNRWA clinics, any reviewers do not affect their income because there is no payment for treating and the income is constant. So, there is a need to find a policy and incentives to encourage public and UNRWA employees in order to improve the quality of the service.

\section{Accident management}

The first aspect of accident management is having a protocol for dealing with sharp instruments during dental care procedures. According to $\mathrm{CDC}$, accident management protocol, includes stopping the procedure, washing the affected area immediately with soap or disinfectant and water, using sterile water in case of exposure of mucous membrane, assessing the depth of injury, then checking the instrument, whether it was contaminated with blood or any body fluids, assessing the risk factors for the patient and the immunity status of the dentist for HBV and finally, taking of prophylaxis in the case of exposure to HBV, HIV, HCV ( Hepatitis C Virus) [33].

Nearly (50\%) of participants have such protocol, to deal with accidents during dental care procedures, this percentage is low compared with another one in which $(81.0 \%)$ of dentists had a clear protocol for needle stick emergency treatment and other sharps accidents [19]. The low percentage can be due to low knowledge or low awareness among dentists. The second important aspect of accident management was included in this study is having a puncture-resistant container for sharp instruments in the clinic. This study shows that a high percentage of the participants $(90.60 \%)$ have a puncture-resistant container for sharp instruments in their clinics. This result is better compared with another one in which (88.4\%) of dentists have puncture-resistant containers for sharp instruments [19]. The practitioners in this field reflect good knowledge, high awareness toward themselves and other people. Medical waste disposal is the third important aspect of accident management included in the current study. Mercury, silver, lead, blood, sharps, and chemicals should be managed as hazardous waste to protect the environment from environmental disasters. A very low percentage of participants in our study $(24.90 \%)$ 
has methods to dispose of their medical waste, this indicates a very big problem regarding cross-infection transmission for dentists and the community. The reasons for this problem should be dealt with seriously by the competent committees. In another study $(81 \%)$ of responses were non-regulated general medical waste procedure which produced within their dental offices, and the medical waste is disposed of in the general clinic trash [34]. The causes of such a problem may be because of low knowledge about the importance of methods to dispose of its medical wastes, no supervision, or the high cost of these methods. Our study also, revealed that $(55.30 \%)$ of the participants complied with accident management, this low percentage put dental practitioners in danger. In the same vein, $(84.20 \%)$ of participants ask their patients about their medical history. This result is better than the documented one in an Indian study in which (52\%) of Indian dentists had the habit of taking a medical history for all dental patients [35]. Although patients may not tell the dentist about the real infectious situation, the dentist should ask about the medical history of each patient in many ways to protect himself, his staff, and his clients. According to CDC guidelines, each accident in the clinic should be documented to prevent all sharp-related injuries and the transmission of blood-borne infections [36]. In this way, the dentist can also protect himself. Only (21.30\%) of participants document accidents which reflects a lack of knowledge and skills. Another study revealed that only (33.9\%) of HCWs documented their injuries [37].

As in all domains of this study, there were significant differences in accident management among participants attributed to the Nablus and Tulkarm variable in favor of the Tulkarm district " $\mathrm{P}<0.05$ ". The T-test showed that Tulkarm dental clinics with means $=0.76$ were more compliant to applying accident management in their clinics than Nablus dental clinics with a mean $=0.65$. Significant differences also were presented in accident management among participants attributed to the ownership variable " $\mathrm{P}<0.05^{\prime \prime}$. The Post-Hoc test showed that private clinics with means $=0.70$ are applyed accident management more than other clinics (public and UNRWA). This highlighted that a private clinic dentist is very careful and keen not to have an accident in his/her clinic. Thus, that will keep both the clinic's reputation and the clients. While in public and UNRWA clinics, the dentist gets a fixed salary, no strict health system that sues the dentist in case of accidents resulted from negligence, and irresponsibility toward patients and society due to the lack of knowledge and awareness.

\section{Limitations of the study}

This questionnaire was distributed to dental practitioners during the peak period of COVID-19 pandemic in Palestine, in which all health care institutions were closed except urgent medical procedures. Thus, the author was unable to verify the authenticity of the answers, due to the inability to conduct an inspection and check-up.

\section{Conclusions}

In conclusion, this study, which was done among dental clinics in Tulkarm and Nablus districts revealed a critical need for strict adherence and compliance to infection control protocol among dentists in both districts to prevent the transmission of infectious diseases in any health care setting.

\section{Recommendations}

Evaluation of an actual infection control protocol of sampling tools, instruments, surfaces and culture them as well as checking their disinfection and sterilization status and evaluation of the patient's confidence and perception of dental clinics regard infection control practices. In addition to the establishment of the infection control committee to plan, monitor and control, and also evaluate the infection control measures in oral health care settings. This suggested committee will also be responsible for improving, developing, and updating infection control strategies and standards, identifying training course's needs and establishing training modules taking into consideration COVID 19 pandemic and the documentation of the medical history of patients.

\section{Material and method \\ Study design}

A descriptive, quantitative, and cross-sectional design was adopted in order to assess the level of knowledge and compliance about infection control measures in dental clinics.

\section{Study settings}

This study has taken place in the dental clinics in Nablus and Tulkarm Governorates due to the proximity in the distance.

\section{Study population}

A universal sample of dentists who were registered in the Palestinian dental association to practice dentistry in Nablus and Tulkarm districts have been recruited. The sample size was estimated at a $95 \%$ Confidence Interval (C.I) accepting a 5\% error margin using the sample size calculator (www.raosoft.com) for a population of nearly 690 dentists practicing in both districts [38]. The total 


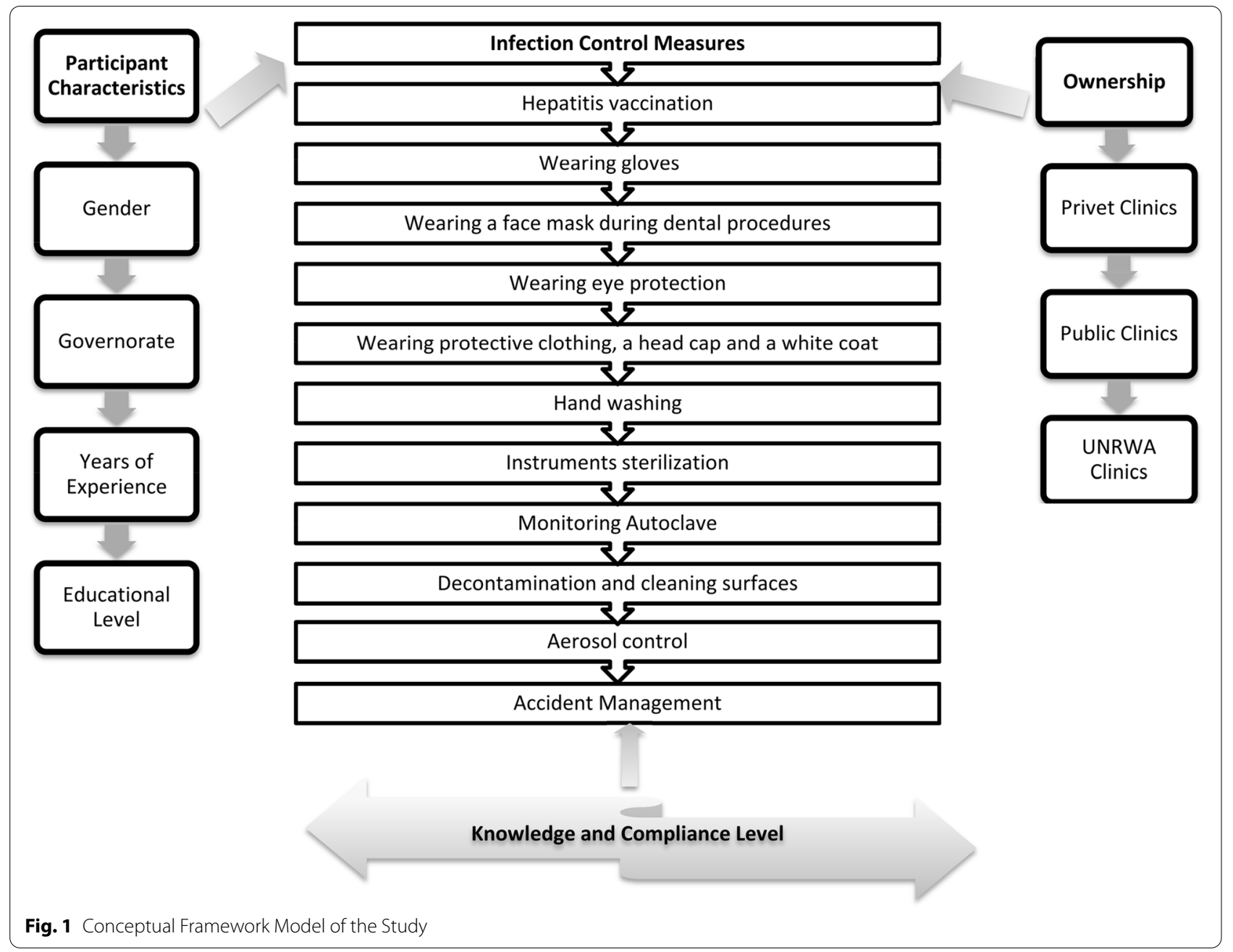

number of the study population was 675 dentists. The study targeted a sample of 245 dentists, and therefore the ratio of the study sample to the total study population was $245 / 675=0.362$ dentists. The dentists who were working in public dental clinics, and UNRWA (United Nations Relief and Works Agency For Palestine Refugees in The Near East) have been excluded to be taken obligatory in both districts (15 dentists) due to their low numbers. Based on the foregoing, the sample has been taken from each governorate according to the following formula: the number of dentists in the governorate $\times 0.362$ regardless of age, gender, educational level, and years of practice. The objectives of the indicators had been accomplished to be representative and generalized.

\section{Period of the study}

The questionnaire was distributed between July and August 2020 which was the peak of COVID-19 (Coronavirus disease-2019) in Palestine via email to 265 dentists in Nablus and Tulkarm districts. Participants who did not respond to the first mailing were reminded 3 weeks later through an emailed memo.

\section{Study tool and variables}

This study covered 10 issues of the basic guidelines for infection control in dental clinics, according to CDC (Center Of Disease Control And Prevention) and Palestinian infection and training protocols to assess the dentists' knowledge and compliance with the basic guidelines of infection control in dental clinics. The questionnaire was comprising 63 questions. The first part of the questionnaire asks about the demographic profile. Then each participant has answered a series of questions about the infection control measures that they have been done regularly during clinical practice. The main variables that have been analyzed during this study were the infection control measurements using in dental clinics, knowledge, and compliances about/with these measures, see Fig. 1. 


\section{Validity and reliability}

To test the suitability of the current study method, a pilot study was carried out on a random sample of 20 dentists. The validity of the study tool was evaluated and modified by a group of experts and the coefficient of reliability (Cronbach's alpha) was acceptable 0.753 .

\section{Statistical analysis}

Collected data was reviewed for completeness and accuracy. Initially, MS excel has been utilized for coding the data obtained through the questionnaire and resulting answers has been recorded and processed using the Statistic Package for the Social Sciences (IBM SPSS for Windows, Version 20.0). Descriptive statistics and bivariate analysis have been carried out using the Chisquare test to discuss the differences in infection control measures, knowledge, and compliance according to demographic characteristics. The question that has more than $80 \%$ positive answers was judged as the highest score, moderate if positive answers were between 60 and $79 \%$; whereas, low if $<60 \%$ positive answers. One-way ANOVA, Post-Hock tests, and others have been used to compare means overall compliance by ownership of the clinic. Statistical significance has been set at " $\mathrm{p}<0.05$ ".

\begin{abstract}
Abbreviations
CDC: Center Of Disease Control And Prevention; COVID-19: Coronavirus Disease 2019; HBV: Hepatitis B Virus; HCV: Hepatitis C Virus; HIV: Human Immunodeficiency Virus; PPE: Patient Protective Equipment's; SARS-CoV-2: Severe Acute Respiratory Syndrome Coronavirus; TB: Tuberculosis; UNRWA: United Nations Relief and Works Agency For Palestine Refugees in The Near East; WHO: World Health Organization.
\end{abstract}

\section{Acknowledgements}

The authors kindly acknowledge the dentists who have approved to share with this study in Nablus and Tulkarm Districts.

The views and opinions expressed in this article are those of the authors and do not necessarily reflect the official policy or position of any affiliated agency of the authors.

\section{Authors' contributions}

All authors listed have contributed to the work and approved it for publication. The authors have worked in an organized manner. W.M has supervised the work, communicated with the key persons and wrote the manuscript. A.S has designed the study, collected the data, and did the statistical analysis. L.K has reviewed the data and the final manuscript for approval. The author(s) read and approved the final manuscript.

\section{Funding}

This study has been conducted in Partial Fulfillment of the Requirements for the Degree of Master of Public Health Management, Faculty of Graduate Studies, An-Najah University, Nablus-Palestine without any funding.

\section{Availability of data and materials}

The datasets of the current study are available from the corresponding author on reasonable request.

\section{Declarations}

\section{Ethics approval and consent to participate}

To carry out this study, all methods were carried out in accordance with relevant guidelines and regulations. Approval from the Office of the Institutional Review Board (IRB) of An-Najah National University was provided. Informed consents have been fulfilled as participation in this study was voluntary. Information about the aim of this study was provided to the participants. They also could withdraw from the study at any time without any punishment. It was confirmed that strict privacy was maintained all the time of the study period, so the questionnaire was recorded via using serial numbers.

\section{Consent for publication}

Not applicable.

\section{Competing interests}

The authors declare that they have no competing interests.

\section{Author details}

1Public Health Management Program, Faculty of Graduate Studies, An-Najah University, Nablus, Palestine. ${ }^{2}$ Pathology and Medical Laboratory Sciences Department, Medicine and Health Science college, An Najah National University, Nablus, Palestine. ${ }^{3}$ Head of Quality Assurance Department at NBU, Scientific Centers, An Najah National University, Nablus, Palestine. ${ }^{4}$ Master of Public Health Management, Faculty of Graduate Studies, An-Najah University, Nablus, Palestine. ${ }^{5}$ Medicine and Health Science College, An Najah National University, Nablus, Palestine.

Received: 6 July 2021 Accepted: 1 November 2021

Published online: 20 December 2021

\section{References}

1. Yamalik N, Dijk W. Analysis of the attitudes and needs/demands of dental practitioners in the field of patient safety and risk management. Int Dental J. 2013;291-297. https://doi.org/10.1111/idj.12081.

2. Piryani RM, Shrestha T, Neupane MS. Personal habits and hygiene behavior of students entering nursing education. J Chitwan Med College. 2018;8(2):37-40. https://doi.org/10.3126/jcmc.v8i2.23736.

3. Chitaladze T, Kazakhashvili N. Knowledge, Attitudes And Perception Among Patients Towards Cross-Infection Control Measures In Dental Clinics In Georgia Before The COVID-19 Pandemic. Georgian Med News. 2020;309:161-6 PMID: 33526748.

4. Gaupp, R., Dinius, J., Drazic, I., and Ko.rner, M. Long-term effects of an e-learning course on patient safety: A controlled longitudinal study with medical students. PLOS ONE. 2019. https://doi.org/10.1371/journal.pone.0210947

5. McCacarthy, G., and Briton, J. A Survey of Final-Year Dental, Medical and Nursing Students: Occupational Injuries and Infection Control. J Can Dent Assoc. 2000; 561. PMID: 11091478.

6. Kochhar, A., Bhasin, R., Kaur Kochhar, G., and Dadlani, H. COVID-19 Pandimc and Dental Practice. Int J Dentistry. 2020;5. DOI: https://doi.org/10 1155/2020/8894794.

7. Vilar-Compte D, Camacho-Ortiz A, Ponce-de-León S. Infection Control in Limited Resources Countries: Challenges and Priorities. Curr Infect Dis Rep. 2017;19:20. https://doi.org/10.1007/s11908-017-0572-y.

8. Halfon, P., Staines, A., and Burnand, B. Adverse events related to hospital care: a retrospective medical records review in a Swiss hospital.Pub Med. 2017;29(4):527-533. DOI: https://doi.org/10.1093/intahc/mzx061.

9. McCarthy, B. C., Tuiskula, K. A., Driscoll, T. P., and Davis, A. M.. Medication errors resulting in harm: Using chargemaster data to determine associated with cost of hospitalization and length of stay. Pub Med. 2017;102107. DOI: https://doi.org/10.2146/ajhp160848

10. Tada, A., Watanabe, M., and Senpuku, H. Factors affecting changes in compliance with infection control practices by dentists in Japan. Am J Infection Control. 2015:43:95-97. PMID: 24463798; PMCID: PMC7767590. 
11. Bourgeois D, Dussart C, Saliasi I, Laforest L, Tramini P, Carrouel F. Observance of Sterilization Protocol Guideline Procedures of Critical Instruments for Preventing latrogenic Transmission of Creutzfeldt-Jakob Disease in Dental Practice in France, 2017. Int J Environ Res Public Health. 2018;15(5):853. https://doi.org/10.3390/ijerph15050853.

12. Dagher J, Sfeir C, Abdallah A, Majzoub Z. Infection Control Measures in Private Dental Clinics in Lebanon. Int J Dent. 2017;2017:5057248. DOl: 10.1155/2017/5057248. Epub 2017 May 31. PMID: 28642792; PMCID: PMC5470049.

13. Akhtar, F., \& Rehman, S. A Public Health Analysis of Gaps in Disease Monitoring and Opportunities for Improved Care for the Management of Hepatitis B and C. Cureus, 2018;10(1), e2077. https://doi.org/10.7759/ cureus.2077.

14. Yasutake, Y., Hattori, S.-I., Tamura, N., Matsuda, K., Kohgo, S., and Mitsuya, $\mathrm{H}$. Structural features in common of HBV and HIV-1 resistance against chirally-distinct nucleoside analogues entecavir and lamivudine. Pub Med 2020; 10(1).

15. CDC. 2007 Guideline for Isolation Precautions: Preventing Transmission of Infectious Agents in Healthcare Settings. 2019 US: CDC.

16. CDC. (2020, Aug 19). Using Personal Protective Equipment (PPE). CDC.

17. WHO. (October, 2019) Right to health 2018 / World Health Organization. Regional Office for the Eastern Mediterranean.

18. Nazzal, Z., and Sobuh, I. Risk factors of hepatitis B transmission in northern Palestine: A case - Control Study. BMC Research Notes 2014;7, p. p.190.

19. Mahasneh, A. M., Alakhras, M., Khabour, O., Alsa'd, A., and Al-Mousa, D. S. Practices of Infection Control Among Dental Care Providers: A Cross Sectional Study. Clinical, Cosmetic and Investigational Dentistry. 2020;12:281-289. DOI https://doi.org/10.2147/CCIDE.S261171

20. Hroub, A. A. Assessment of the Infection Control System in Dental Clinics in Hebron District (Unpublished master's thesis). 2017 Jerusalem-Palestine: Al-Quds University.

21. Elshanti A, Aldirawi A, Al-Jamal A, Jaser S, Al-Astal R, et al. Compliance of Dentists with Infection Control Practices in Primary Health Care Centers in Gaza Strip, Palestine. An Epidemiol Public Health. 2021; 4(1): 1047.

22. Jibreen, S., Khouri, A. T., and Dababneh, R. Compliance With The Use Of Personal Protective Equipment Among Dentists Working At The Royal Medical Services. ResearchGate. 2009

23. Khan, w., and Chughtai, A. A. Use of personal protective equipment to protect against respiratory infections in Pakistan: A systematic review. J Infection Public Health 2020;13(3), pp. 385-390. DOI: 10.1016/j. Jeep.2020.02.032. Epub 2020 Mar 4.

24. Diatech. Your Ultimate Guide to Dental Sterilization. 2020 Diatech. https://diatechusa.com/blog/guide-dental-sterilization/

25. Schneiderman, M. T., \& Cartee, D. L. Surface Disinfection. Infection Control in the Dental Office: A Global Perspective 2019; 169-191. https://doi.org/ 10.1007/978-3-030-30085-2_12

26. Ibrahim N, Alwafi H, Sangoof S, Turkistani A, Alattas B. Cross-infection and infection control in dentistry: Knowledge, attitude and practice of patients attended dental clinics in King Abdulaziz University Hospital, Jeddah, Saudi Arabia. J Infect Public Health. 2017;10(4):438-45. https:// doi.org/10.1016/j.Jeep.2016.06.002 Epub 2016 Jul 14.

27. Idris,M. Assessment of infection control in public dental clinics in Khartoum State (MSc Dissertation), Sudan. Khartoum State, Sudan: University of the Western Cape. 2012

28. Jolanta Szymańska: Dental bioaerosol as an occupational hazard in a dentist's workplace. Ann Agric Environ Med 2007, 14, 203-207.

29. Al-Amad SH, Awad MA, Edher FM, Shahramian K, Omran TA. The effect of rubber dam on atmospheric bacterial aerosols during restorative dentistry. J Infect Public Health. 2017;10(2):195-200. DOl: 10.1016/j. jeep.2016.04.014. Epub 2016 May 24. PMID: 27234605.

30. Sanghvi A, Chand Nagda R, Raju Jagdish. A cross-sectional study on frequency of rubber dam usage among dentists practicing in Maharashtra India. Saudi Endodontic J. 2018;8:39-43. https://doi.org/10.4103/sej.sej_ 9216.

31. Choi, J.-O., Yu-Jin, C., and Hee Nam, S. Study on the prevention of crossinfection by aerosols during scaling. Biomedical Research 2018;29.DOI: https://doi.org/10.4066/biomedicalresearch. 29-18-839.

32. Qamar MK, Shaikh BT, Afzal A. What Do the Dental Students Know about Infection Control? A Cross-Sectional Study in a Teaching Hospital, Rawalpindi, Pakistan. Biomed Res Int. 2020:3413087. https://doi. org/10.1155/2020/3413087. PMID: 32596299; PMCID: PMC7285392.
33. Abubakar S, Iliyasu G, Dayyab FM, Inuwa S, Tudun Wada RA, Sadiq NM, Gadanya MA, Sheshe AA, Mijinyawa MS, Habib AG. Post-exposure prophylaxis following occupational exposure to HIV and hepatitis B: an analysis of a 12-year record in a Nigerian tertiary hospital. J Infect Prev. 2018;19(4):184-189. DOI: https://doi.org/10.1177/1757177417746733. Epub 2017 Dec 17. PMID: 30013623 ; PMCID: PMC6039908.

34. Asiri, A. A., Baseer, M. A., Alsanea, J. A., Binalrimal, S., and Almeslet, A. H. (2019, May-August). Knowledge, Attitude, and Practice of Dental Health Professionals Toward Management of Dental Waste in the Aseer Region, Kingdom of Saudi Arabia. Journal of Oral Health and Community Dentistry, 13(2).DOl: https://doi.org/10.5005/JP-journals-10062-0048.

35. Bommireddy VS, Pachava S, Sanikommu S, Vinnakota N, Talluri D, Ghanta BK. Infection control measures among dental practitioners in a Southern state of India: A cross-sectional study. Indian Assoc Public Health Dentistry. 2016;14(3):302-7.

36. CDC. (2014, Jun 6). Preventing Needlestick Injuries in Health Care Settings. National Institute for Occupational Safety and Health.

37. Cui, Z., Zhu, J., Zhang, X., Wang, B., and Li, X. Sharp injuries: a cross-sectional study among health care workers in a provincial teaching hospital in China.Environ Health Prev Med. 2018;23. PMID: 29316884 PMCID: PMC5761091 DOl: https://doi.org/10.1186/s12199-017-0691-y.

38. Palestinian Health Information Center (PHIC) -MOH. (Jul-2019). Palestine. Ramalla: Palestinian Ministry of Health

\section{Publisher's Note}

Springer Nature remains neutral with regard to jurisdictional claims in published maps and institutional affiliations.

Ready to submit your research? Choose BMC and benefit from

- fast, convenient online submission

- thorough peer review by experienced researchers in your field

- rapid publication on acceptance

- support for research data, including large and complex data types

- gold Open Access which fosters wider collaboration and increased citations

- maximum visibility for your research: over $100 \mathrm{M}$ website views per year

At BMC, research is always in progress.

Learn more biomedcentral.com/submissions 